\title{
PATRIMONIO PÚBLICO, GESTÃO E CONTROLE COM O ADVENTO DA LRF: GESTÃO DE MATERIAS IMOBILIZADOS NO ESTADO DE MATO GROSSO
}

\author{
Alex Sabino dos Santos 1 \\ Eder Eugenio Munhão \\ Ariel Lopes Torres ${ }^{3}$
}

\section{RESUMO}

Este artigo científico de revisão bibliográfica tem como objetivo analisar as características e definições dos bens que integram o Patrimônio Público, além de se exemplificar as principais mudanças causadas na gestão patrimonial pela implantação da Lei de Responsabilidade Fiscal, que, no Estado de Mato Grosso, é gerida pelo software SigPat. O referido sistema é utilizado por todos os entes estatais de Mato Grosso, e tem a capacidade de gerar relatórios diversos, que facilitam a gestão de bens patrimoniais estatais. Conclui-se que a LRF veio para gerir estas lacunas, garantindo a transparência, com maior controle e responsabilidade imputada a cada gestor ligado ao governo, que tenha sob seu poder, bens patrimoniais públicos de quaisquer espécies. O sistema de gestão patrimonial SigPat, unifica esta gestão, garantindo, na forma da Lei, a responsabilidade a quem é de dever.

Palavras chaves: LRF, patrimônio público, SigPat

\section{INTRODUÇÃO}

Objetivando a compreensão da gestão de Patrimônio Público, suas relações com a Lei de Responsabilidade Fiscal, e sua aplicação no Estado de Mato Grosso, serão aqui expostos revisão bibliográfica referente ao tema, bem como sua aplicação real dentro de órgãos públicos estaduais. Em um primeiro momento, serão apresentados conceitos como: Administração Pública, bens públicos, depreciação, domínio público, para, então, apresentar o software que gere tais bens na Administração Pública do Estado de Mato Grosso.

\section{REFERENCIAL TEÓRICO}

\subsection{ADMINISTRAÇÃO PÚBLICA}

Para entendermos a Administração Pública é necessário partirmos de conceitos iniciais, como por exemplo, o Estado, segundo Meirelles (2005), que é constituído por três elementos indissociáveis: Povo, Território e Governo Soberano, sendo que o Governo Soberano exerce as funções de auto-organização e autodeterminação através do poder emanado pelo povo.

\footnotetext{
${ }^{1}$ Acadêmico do Curso de Ciências Contábeis da UNEMAT - Campus de Tangará da serra, email: alexsabino@unemat.br

${ }^{2}$ Mestrando em Ciências Contábeis do Minter UNISINOS/UNEMAT, e-mail: edermunhao@unemat.br

${ }^{2}$ Mestre em Administracion Y Finanzas pela Universidade de Extremadura (2003), Professor do curso de Ciências Contábeis da UNEMAT - Campus de Tangará da Serra, e-mail: ariel@ unemat.br
} 
A Administração Pública, ainda segundo Meirelles,

Em sentido formal, é o conjunto de órgãos instituídos para a consecução dos objetivos do Governo; em sentido material, é o conjunto das funções necessárias aos serviços públicos em geral; em acepção operacional, é o desempenho perene e sistemático, legal e técnico, dos serviços próprios do Estado ou por ele assumidos em beneficio da coletividade.

A administração, para exercer as suas atividades, faz uso de alguns instrumentos, e um deles é Domínio Público.

\subsection{DOMÍNIO PÚBLICO}

Desde os mais antigos grupos sociais, sempre existiu a necessidade de haver algum tipo de regulamentação e dominação do Estado sobre alguns bem de uso coletivo. Se o Estado não disponibiliza à sociedade esses bens, deixa de cumprir suas finalidades sociais que visam o bem comum, tornando impraticável o convívio e a vida em sociedade.

Considerando o Estado como "a ordem jurídica soberana que tem por fim a o bem comum de um povo em um determinado território" (DALLARI, 1998 p.118), ele pode normatizar sobre a propriedade de bens públicos e a de bens de particulares.

\footnotetext{
Alguns bens pertencem ao próprio Estado; outros, embora pertencentes a particulares, ficam sujeitos às limitações administrativas impostas pelo Estado; outros, finalmente, não pertencem a ninguém, por inapropriáveis, mas sua utilização subordina-se às normas estabelecidas pelo Estado. Este conjunto de bens sujeitos ou pertencentes ao Estado constitui o domínio público, em seus vários desdobramentos. (MEIRELLES, 2001 p.476).
}

Para essa dominação, o Estado necessita de um regime jurídico adequado, que além de especificar a composição e a utilização da propriedade, cria regras de proteção contra os ilegítimos ou danosos, quer provindo de particulares ou do próprio Estado. A dominação e a regulamentação, nos Estados Modernos, originam-se de um regime jurídico adequado que especifica sua composição e utilização, além de criar regras de proteção "contra atos ilegítimos, ou danosos, quer provindos de particular, quer do próprio Estado" (BASTOS, 1994, p. 103).

O domínio público em sentido amplo é o poder de dominação ou de regulamentação que o Estado exerce sobre os bens do seu patrimônio (bens públicos), ou sobre os bens do patrimônio privado (bens de particulares de interesse público), ou sobre coisa inapropriaveis individualmente, mas de fruição geral da coletividade (res nullis).(MEIRELLES, 2001 p.477) 
Patrimônio público, gestão e controle com o advento da LRF: gestão de materiais imobilizados no estado de Mato Grosso

Alex Sabino dos Santos, Eder Eugenio Munhão, Ariel Lopes Torres

Não se pode confundir propriedade com dominação e regulamentação dos bens patrimoniais. A propriedade poder ser pública ou privada, enquanto dominação e regulamentação estão voltadas para o domínio público dos bens patrimoniais.

Os bens de propriedade do Estado são considerados bens públicos e compõem o patrimônio público, sendo "formado por bens de todas as naturezas e espécies que tenham interesses para a Administração e para a comunidade Administrada". (MEIRELLES, 2001 p.478)

\subsubsection{Bens públicos e suas classificações}

“Os bens públicos são o conjunto de coisas corpóreas e incorpóreas, móveis, imóveis e semoventes de que o Estado se vale para puder atingir as suas finalidades". (BASTOS, 2002 p.499).

Inicialmente, conforme o Código Civil (art. 98 e ss.), os bens públicos e particulares devem ser divididos, esclarecendo-se que os do domínio nacional, que pertencem à União, aos Estados e aos Municípios, são públicos, e os particulares são todos os outros, pertencentes a quem quer que seja. São bens públicos os que, originariamente integrando o patrimônio nacional, os bens transferidos a autarquias e fundações públicas. (MEIRELLES, op. cit., p. 435)

Os Bens de uso comum do povo são aqueles que, por determinação legal ou por sua própria natureza, podem ser utilizados por todos em igualdade de condições, sem a necessidade de consentimento individualizado por parte da Administração Pública, por exemplo: praças, estradas, água do mar, rios e etc.

Em relação aos Bens de uso especial, são todas as coisas, móveis e imóveis corpóreas ou incorpóreas, utilizadas pela Administração Pública pra realização de suas atividades e consecução de seus fins. (DI PIETRO, 2OO1, p.532)

Os Bens dominiais (patrimônio disponível) são bens que possuem características diferentes, pois podem ser utilizados em qualquer fim, ou podem ser alienados de acordo com a necessidade do Estado, e geralmente produzem renda.

Ainda dentro da contabilidade pública, a classificação dentro dos critérios contábeis e a seguinte:

Bens imóveis: são prédios e instalações de uso público coletivo;

Bens de natureza industrial: instalações destinadas a produção industrial para o próprio Estado, com máquinas, ferramentas, móveis, etc;

Bens de defesa nacional: são os bens destinados às forças armadas nacionais tais como navios, quartéis, tanques de guerra etc;

Bens científicos, culturais e artísticos: são bens destinados a exatamente a este fim, por exemplo: biblioteca, museus, zoológicos etc; 
Patrimônio público, gestão e controle com o advento da LRF: gestão de materiais imobilizados no estado de Mato Grosso

Alex Sabino dos Santos, Eder Eugenio Munhão, Ariel Lopes Torres

Bens de natureza agrícola: fazendas pertencentes ao Estado, campos de experimentação;

Bens semoventes: seriam os animais pertencentes ao Estado com a finalidade de acervo, frota de tração animal;

Valores: ações, apólices, joias, moedas, etc. Em geral são bens de terceiros recolhidos pelo Estado para quitação de dívidas;

Créditos: são resíduos ativos ou dívida ativa, assim como os direitos de receber valores de servidores através de sanções impostas aos mesmos.

O art. 105 da Lei 4320, de 1964, ainda classifica os itens da substância patrimonial em dois grandes grupos: o Ativo Financeiro e o Ativo Permanente. O primeiro são valores que podem ser movimentados independentes de autorização legislativa e o segundo agrupa os bens e valores que, se movimentados, causam variações no balanço patrimonial, necessitando, portanto, de autorização legislativa para movimentação.

\subsubsection{Depreciação de Bens}

Por depreciação de bens do ativo imobilizado entende-se a perda do valor dos elementos classificáveis - resultado de desgaste por uso, ação da natureza ou obsolescência normal. Esta perda de valor deve ser registrada, conforme indica o site da Receita Federal:

Referida perda de valor dos ativos, que têm por objeto bens físicos do ativo imobilizado das empresas, será registrada periodicamente nas contas de custo ou despesa (encargos de depreciação do período de apuração) que terão como contrapartida contas de registro da depreciação acumulada, classificadas como contas retificadoras do ativo permanente (RIR/1999, art. 305).

A taxa de depreciação aplicável é obtida mediante a divisão de $100 \%$ pelo prazo de vida útil, sendo mensal, trimestral ou anual, apurando-se, dessa forma, a taxa periódica a ser utilizada, ainda conforme Regulamento do Imposto de Renda de 1999.

\subsubsection{Controle Patrimonial}

Os bens patrimoniais são controlados por repartição específica, dentro de cada ente estatal, sendo responsabilidade de cada setor. Conforme imposição legal, de acordo com a Lei Federal n 4.320, de 17 de março de 1964:

Art. 94. Haverá registros analíticos de todos os bens de caráter permanente, com indicação dos elementos necessários para a perfeita caracterização de cada um deles e dos agentes responsáveis pela sua guarda e administração.

Art. 95. A contabilidade manterá registros sintéticos dos bens móveis e imóveis. 
Patrimônio público, gestão e controle com o advento da LRF: gestão de materiais imobilizados no estado de Mato Grosso

Alex Sabino dos Santos, Eder Eugenio Munhão, Ariel Lopes Torres

Art. 96. O levantamento geral dos bens móveis e imóveis terá por base o inventário analítico de cada unidade administrativa e os elementos da escrituração sintética na contabilidade.

Cabe ao ente estatal responsável pelo bem patrimonial:

- registrar as incorporações e baixas dos bens existentes;

- registrar e informar a localização dos bens, bem como controlar ;

- controlar a movimentação de bens;

- registrar os responsáveis pelos bens; e emitir relatórios dos bens de acordo com local de utilização.

\subsection{LEI DE RESPONSABILIDADE FISCAL}

A Lei Complementar $n^{\circ} 101$, de 04 de maio de 2000 - conhecida com Lei de Responsabilidade Fiscal (LRF), teve como relatores o Deputado Pedro Novais-MA e o Senador Jefferson Peres-MA e entrou em vigor em 04 de maio de 2000. Seus principais objetivos são incentivar a participação popular no âmbito fiscal e propor os meios pelos quais os interessados possam se utilizar para fiscalizar a utilização do orçamento público, e dar publicidades aos gastos públicos, possibilitando assim uma maior transparência por parte da Administração Pública em relação aos seus atos.

Esta lei está fundamentada especificamente no $\S 9^{\circ}$ do art. 165 da Constituição Federal, bem como em seus artigos 163 a 169, que deixam clara a intenção de promover a eficiência da administração financeira, dando à sociedade maior poder de controle sobre o Estado. Seus pilares são a responsabilidade, o controle e a transparência, pontos estes considerados quesitos fundamentais para a boa administração pública.

No que diz respeito à transparência, os artigos 48 e 49 da LRF, alterada pela Lei Complementar 131/2009 são claros quanto aos critérios adotados:

Art. 48. São instrumentos de transparência da gestão fiscal, aos quais será dada ampla divulgação, inclusive em meios eletrônicos de acesso público: os planos, orçamentos e leis de diretrizes orçamentárias; as prestações de contas e o respectivo parecer prévio; o Relatório Resumido da Execução Orçamentária e o Relatório de Gestão Fiscal; e as versões simplificadas desses documentos.

Parágrafo único. A transparência será assegurada também mediante:

I - incentivo à participação popular e realização de audiências públicas, durante os processos de elaboração e discussão dos planos, lei de diretrizes orçamentárias e orçamentos;

II - liberação ao pleno conhecimento e acompanhamento da sociedade, em tempo real, de informações pormenorizadas sobre a execução orçamentária e financeira, em meios eletrônicos de acesso público;

III - adoção de sistema integrado de administração financeira e controle, que atenda a padrão mínimo de qualidade estabelecido pelo Poder Executivo da União e ao disposto no art. 48-A. 
Patrimônio público, gestão e controle com o advento da LRF: gestão de materiais imobilizados no estado de Mato Grosso

Alex Sabino dos Santos, Eder Eugenio Munhão, Ariel Lopes Torres

Art. 48-A. Para os fins a que se refere o inciso II do parágrafo único do art. 48, os entes da Federação disponibilizarão a qualquer pessoa física ou jurídica o acesso a informações referentes a: (artigo acrescido p/LC 131/2009) I - quanto à despesa: todos os atos praticados pelas unidades gestoras no decorrer da execução da despesa, no momento de sua realização, com a disponibilização mínima dos dados referentes ao número do correspondente processo, ao bem fornecido ou ao serviço prestado, à pessoa física ou jurídica beneficiária do pagamento e, quando for o caso, ao procedimento licitatório realizado;

II - quanto à receita: o lançamento e o recebimento de toda a receita das unidades gestoras, inclusive referente a recursos extraordinários.

Art. 49. As contas apresentadas pelo Chefe do Poder Executivo ficarão disponíveis, durante todo o exercício, no respectivo Poder Legislativo e no órgão técnico responsável pela sua elaboração, para consulta e apreciação pelos cidadãos e instituições da sociedade.

Parágrafo único. A prestação de contas da União conterá demonstrativos do Tesouro Nacional e das agências financeiras oficiais de fomento, incluído o Banco Nacional de Desenvolvimento Econômico e Social, especificando os empréstimos e financiamentos concedidos com recursos oriundos dos orçamentos fiscal e da seguridade social e, no caso das agências financeiras, avaliação circunstanciada do impacto fiscal de suas atividades no exercício.

Deve, então, o gestor em exercício, além de prestar contas à União, divulgar, semestralmente, estas prestações de contas, para devido cumprimento da LRF.

\subsubsection{Lei de responsabilidade fiscal x Patrimônio Público}

Em seus artigos 44, 45 e 46, a Lei de Responsabilidade Fiscal apresenta medidas que se destinam à preservação do patrimônio público. Entre estas medidas, está a que estabelece que o capital resultante da venda de bens móveis, imóveis e de direitos que integrem o patrimônio público não poderá ser aplicado em despesas correntes, excetuando-se casos que a lei autorizativa o destine aos financiamentos de regimes de previdência social, geral e própria de servidores. Partindo deste pressuposto, tais recursos, também chamados de receita de capital, decorrentes de desincorporação por venda de ativos, somente poderão ser aplicados em despesa de capital, desincorporando dívidas passivas por meio de amortização da dívida ou incremento de outro ativo, sempre preservando o valor do patrimônio público.

Assim, esse dispositivo torna-se um aperfeiçoamento do art. 11 da Lei Federal 4320, de 17 de março de 1964, que considera o superávit do orçamento corrente como receita de capital, estabelecendo que esse capital deve ser empregado em financiamento de despesas de capital.

Títulos da dívida pública, tanto estadual quanto municipal, bem como papéis de empresas controladas pelo respectivo ente, também não poderão receber aplicações 
Patrimônio público, gestão e controle com o advento da LRF: gestão de materiais imobilizados no estado de Mato Grosso

Alex Sabino dos Santos, Eder Eugenio Munhão, Ariel Lopes Torres

deste capital disponíveis. Há também proibições quanto à concessão de empréstimos não deve ser utilizado o capital citado para tal fim, tanto para segurados quanto para o poder público ou empresas controladas; e, outra media considerada importante, estabelece que o orçamento não possa consignar dotação para investimentos novos enquanto os que estiverem em andamento não forem adequadamente atendidos, observando-se a contemplação das despesas de conservação do patrimônio público.

\subsubsection{Estado de Mato Grosso gestão patrimonial}

No estado de Mato Grosso, a gestão de patrimônio e feita de maneira unificada através do software de gestão patrimonial Sigpat, adquirido pela SAD (Secretária de Administração) da empresa Linkdata, e começou a operar em janeiro de 2010.

O sistema possui dois módulos: o de gestão de bens de consumo e o de gestão de bens imobilizados, para efeito deste artigo tratará apenas do módulo de gestão de bens imobilizados.

O modulo de gestão DCE bens imobilizados possibilita o controle unificado de todos os bens com características permanentes de cada órgão do Estado, sendo que as operações usuais são: entradas, transferências internas e cadastro de fornecedores. E, concomitante a essas operações, são emitidos os seguintes Relatórios de Entrada de Material - Analítico, Relatórios de Entrada de material - Sintético, Termos de Transferência Interna de Bens, além dos Termos de Responsabilidade, sendo que os mesmos podem ser gerados em diferentes plataformas como:.xml, .pdf, .doc, etc.

O sistema conta ainda com ferramenta de classificação automática dos bens, possibilitando assim lançamentos mais precisos, diminuindo erros de classificação.

\section{METODOLOGIA}

Nesse capítulo se descrevem os procedimentos metodológicos utilizados na elaboração da pesquisa, visando responder o problema e atender os objetivos propostos.

\subsection{CLASSIFICAÇÃO DA PESQUISA}

Silva e Menezes (2001) e Gil (1999), classificam as pesquisas quanto à natureza, forma de abordagem do problema, objetivo e procedimento técnico.

Quanto à natureza a pesquisa pode ser classificada como aplicada, uma vez que foi desenvolvida para responder um problema específico vivenciado no campo profissional. O problema tem uma abordagem qualitativa, na medida em que para respondê-lo se analisou o sistema SigPat, e a bibliografia a respeito da Lei de Responsabilidade Fiscal. 
Patrimônio público, gestão e controle com o advento da LRF: gestão de materiais imobilizados no estado de Mato Grosso

Alex Sabino dos Santos, Eder Eugenio Munhão, Ariel Lopes Torres

No que tange ao objetivo, a pesquisa pode ser considerada como descritiva, uma vez que se fez uma análise descritiva dos resultados obtidos no estudo. No que diz respeito ao procedimento técnico, este pode ser enquadrado como documental, pois foram utilizados os manuais e a LRF.

\section{CONCLUSÃO}

A gestão do patrimônio público apresenta histórico de insuficiência e inadequação operacionais. A LRF veio para gerir estas lacunas, garantindo a transparência, com maior controle e responsabilidade imputada a cada gestor ligado ao governo, que tenha sob seu poder, bens patrimoniais públicos de quaisquer espécies.

O sistema de gestão patrimonial SigPat, adquirido pela SAD unifica esta gestão, garantindo, na forma da Lei, a responsabilidade a quem é de dever, observando-se as prerrogativas e conceituações acadêmicas sobre bens, domínio público, patrimônio público, depreciação, facilitando a gestão com a possibilidade de cadastros, emissão de relatórios, garantindo assim a transparência da gestão.

\section{REFERENCIAS}

BASTOS, Celso Ribeiro. Curso de direito administrativo. São Paulo: Saraiva, 1994.

BRASIL. Constituição Federal, de 05.10.88. Atualizada com as Emendas

Constitucionais Promulgadas.

BRASIL. Decreto 3000 de 26/03/99 (Regulamento do Imposto de Renda - RIR/99) Lei Complementar $n^{\circ}$ 101, de 05.05.2000. . Lei Complementar $\mathrm{n}^{\circ}$ 131, de 27.05.2009. . Lei Complementar $\mathrm{n}^{\circ} 101$, de 4 de maio de 2000 Lei $\mathrm{n}^{\circ}$ 4.320, de 17 de março de 1964.

FRANCO, Wanildo José Nobre. Domínio público - bens públicos. Boletim Jurídico, Uberaba/MG, a. 4, no 158. Disponível em:

<http://www.boletimjuridico.com.br/doutrina/texto.asp?id=989> Acesso em:

29 nov. 2011.

MEIRELLES, Hely Lopes. Direito Administrativo Brasileiro. 22. ed., São Paulo: Malheiros, 1997.

MELLO, Celso Antonio Bandeira de. Curso de Direito Administrativo. 14. ed. São Paulo: Malheiros, 2001. 
Patrimônio público, gestão e controle com o advento da LRF: gestão de materiais imobilizados no estado de Mato Grosso

Alex Sabino dos Santos, Eder Eugenio Munhão, Ariel Lopes Torres

SADDY, André. Lei de Responsabilidade Fiscal e Democratização da Gestão Pública.

Disponível em: <http://jus2.uol.com.br/Doutrina/texto.asp?id=4006> Acesso em: 28

nov.2011. 